\title{
Benthic effects of artificial structures deployed in a tidal estuary
}

\author{
Maritza Mendoza ${ }^{1, *} \&$ Sarah K. HenkeL ${ }^{2}$ \\ ${ }^{1}$ Marine Resource Management Program, Oregon State University, 318 Strand Hall, Corvallis, OR 97331-5503 \\ ${ }^{2}$ Hatfield Marine Science Center, Oregon State University, 2030 SE Marine Science Drive, Newport, OR 97365
}

Received 30 October 2016; Accepted 20 June 2017 Responsible Editor: Gen Kanaya

\begin{abstract}
There has been increased enthusiasm to mitigate the negative effects of fossil fuel consumption through the use of cleaner sources of energy, like marine renewable energy (MRE). Concerns about MRE deployments have motivated research on the ecological effects of these new man-made structures in marine environments. We assessed the extent to which soft-sediment habitats are influenced by the presence of artificial structures deployed in Yaquina Bay, Oregon, USA. Grain size analyses confirmed artificial structures altered the sediment distribution around them with larger grain sizes detected closer to the structures. Infaunal abundances were higher closer to the artificial structures; however, these differences did not result in statistically significant effects on diversity or richness in relation to distance from the structures, nor were they sufficient to cause statistically significant changes in infaunal communities as compared to reference areas. This study provided additional evidence that artificial structures alter their physical environment, but in our study detected differences were less than those observed between the two different regions of the estuary and any effects on infauna were localized and smaller than differences between different regions of the estuary. Conducting these studies in an Oregon estuary provided a good proxy for estimating potential effects of in-stream tidal energy deployments in the Pacific Northwest while also demonstrating the importance of site-specific research.
\end{abstract}

Key words: artificial structures, estuaries, infauna, marine energy, sediment

\section{Introduction}

For decades, people have developed the coast to serve human activities and purposes, such as coastal protection, navigation, fishing, resource extraction and recreation (Halpern et al. 2008). Increasing development and demand on marine ecosystem services, coupled with climate change and pollution, have placed pressure on essential habitats and threatened ecosystem services (Halpern et al. 2008, Hoegh-Guldberg \& Bruno 2010, Widdicombe $\&$ Somerfield 2012). These threats, combined with rising energy demand and the appeal of energy security, have advanced research on non-fossil fuel based energy, which could decrease carbon dioxide emissions, potentially slowing the rate of ocean acidification or other negative effects of climate change (Inger et al. 2009). In particular, investment in marine renewable energy (MRE) as an alternative has increased in the past decade.

The U.S. west coast shows potential for offshore wind,

*Corresponding author: Maritza Mendoza; E-mail, mendo.maritza@ gmail.com wave, and in-stream tidal energy (Bedard et al. 2005, Thresher \& Musial 2010). MRE installations will result in more utilization of the marine environment, which increases the possibility of affecting ocean ecosystems in additional ways. In order to minimize impacts from a new ocean use, researchers have emphasized the need to identify and diminish adverse social and ecological consequences of the planning, installation, and operation of MRE devices (Inger et al. 2009, Punt et al. 2009, Conway et al. 2010, Henkel et al. 2013).

Many ecological concerns of MRE installations focus on the direct interaction of marine organisms with the devices and mooring lines (Boehlert \& Gill 2010, Henkel et al. 2013) as well as disturbance from underwater noise or electromagnetic fields created by the generation of electricity (Gill 2005, Wilson et al. 2010). MRE installations also have been shown to have potential positive effects, becoming artificial reefs and fish aggregating devices (Wilson 2007, Langhamer et al. 2009, Broadhurst \& Orme 2014). However, how these new habitats affect the adjacent seafloor habitat and biological communities still remains uncertain (Connell \& Glasby 1999, Holloway \& Connell 
2002, Perkol-Finkel \& Benayahu 2007). Little research yet exists on the environmental effects of MRE in areas suited for wave or in-stream tidal energy due to the limited installations of such devices, so much remains to be learned about installations on the Pacific continental shelf and in tidal estuaries.

MRE devices directly alter the marine environment by converting some of the benthos from sedimentary habitat to hard structure. Installation activities will cause immediate disturbances directly to the infaunal communities at the site, but it is uncertain if the presence of the structures will have lasting and widespread consequences to the benthic habitat and organisms beyond the footprint of the installed structure. Previous research on various structures in fluid environments have shown that water flow, particularly velocity, changes around the structure (Hiscock et al. 2002, Southard 2006), resulting in sediment erosion known as scour (Southard 2006). Thus, depending on sediment type and flow regimes, the spatial extent of scour and the consequent changes to sediment characteristics will be variable (Miller et al. 2013), making it uncertain the extent to which MRE devices will affect infaunal communities directly surrounding the structure and further away.

Infaunal communities provide important services for the marine ecosystem, especially in shallow and coastal areas. They are players in biogeochemical cycling and a food source for larger organisms, such as demersal fish, crustaceans, and people (Davis et al. 1982, Hogue \& Carey 1982, Yeung et al. 2010, Coates et al. 2014). Additionally, the low mobility of benthic infauna makes them excellent indicators of environmental quality, and they frequently have been used as ecological indicators of various environmental conditions, such as pollutant concentrations, oxygen levels (Pearson \& Rosenberg 1978, Sivadas et al. 2010), and sediment characteristics (Gray 1974, Smith et al. 2001, Coates et al. 2014). A shift in sediment composition has been shown to cause a shift in the community composition from suspension feeders to deposit feeders and negatively correlated with species diversity (Gray 1974, Mannino \& Montagna 1997). Being able to detect how infaunal communities respond to physical changes to their environment as caused by the installation of MRE devices is the first step in determining if larger trophic changes could be realized and the possible implications for the ecosystem and its users.

A case study was designed to study the zone of influence of deployed structures on benthic habitats and communities in an estuarine environment in Yaquina Bay, Oregon. We used the deployed structures as proxies to investigate the effects of the presence of in-stream tidal energy devices because these devices could be deployed in estuarine environments similar to Yaquina Bay. Although these deployed structures have a smaller physical footprint than current tidal energy devices (Polagye et al. 2010), any effects detected could be useful for approximating benthic effects around full-sized devices. We hypothesized that sediment grain size would decrease and the amount of fine sediment in a sample would increase with increasing distance from an artificial structure. Second, we hypothesized that communities surrounding the artificial structures would have different composition and be more diverse as compared to reference site communities. We expected the hypothesized grain size changes would result in heterogeneous sediment conditions around the structure, allowing for overall greater diversity around the artificial structures because infaunal species distributions have been shown to be very closely tied to sediment characteristics (Gray 1974, Coblentz et al. 2015).

\section{Materials and Methods}

\section{Study Area}

Six artificial structures were deployed in Yaquina Bay, a drowned river estuary in Oregon, in February 2008 (Dauble 2010). Each artificial structure was made from 45 cinderblocks (approximately $20 \times 20 \times 40 \mathrm{~cm}$ with two square holes) that were mortared together into a pyramid shape and set into welded steel frames. The size of the structures were approximately $1.2 \mathrm{~m} \times 1 \mathrm{~m}$ and $1 \mathrm{~m}$ tall. (Dauble 2010). The structures were deployed in pairs $100 \mathrm{~m}$ apart at three locations in the bay in 4.5 to $9.5 \mathrm{~m}$ of water and well outside established navigation channels. These artificial structures most likely resemble the foundations of instream tidal energy devices rather than the actual turbines.

The artificial structures originally were marked with buoys, but these were lost over the years. We were only able to relocate the two structures by the finger jetties in the lower bay and one further up, despite multiple sonar scans and diving attempts in 2015. Thus, only three artificial structures were used for this study. We also established two reference sites to characterize benthic conditions and communities not associated with an artificial structure. These sites were in close proximity to the artificial structures and were expected to have similar benthic conditions (i.e. they were not in a channel or on a tidal flat or on a rocky bottom) as those where the artificial structures were originally placed. One reference site was about $50 \mathrm{~m}$ from the artificial structures by the jetties in the lower bay and the other was at least $50 \mathrm{~m}$ from the artificial structure in the upper bay. We sampled five total sites: Artificial structures AS1, AS2 and the "Jetty" reference site were co-located downstream of the Yaquina Bay bridge, while AS4 and the "Bay" reference site were co-located upstream (Fig. 1). These stations each were sampled once in March or April 2015.

\section{Field Collections and Laboratory Analysis}

We used SCUBA to reach the artificial structures and collect sediment cores on two $15 \mathrm{~m}$ transects radiating out from each artificial structure (Fig. 2). One $15 \mathrm{~m}$ transect was oriented parallel (along) to the shore, typically in a 


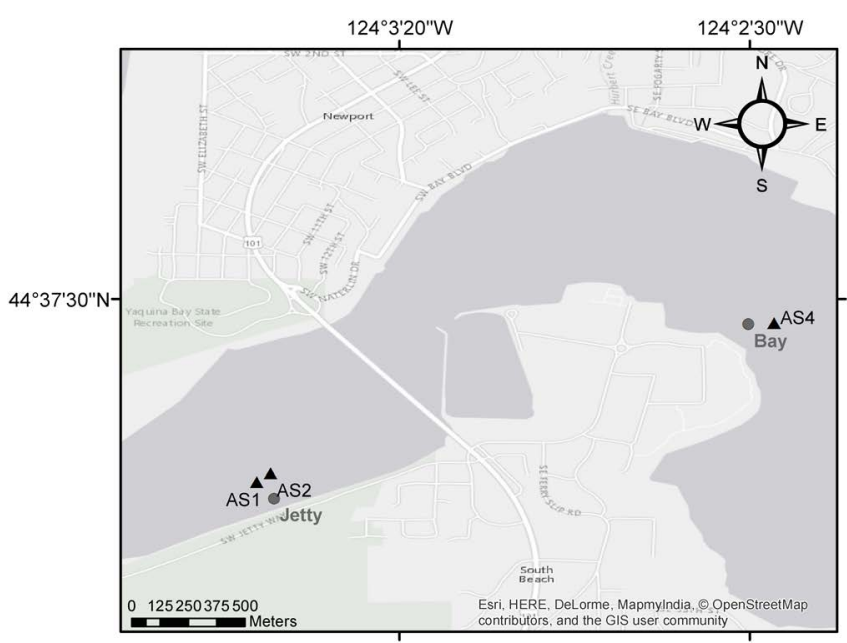

Fig. 1. Location of artificial structures (AS; triangles) and reference sites (Jetty and Bay; circles) in Yaquina Bay. AS1, AS2 and the Jetty reference site were closer to the mouth of the estuary (downstream). AS4 and the Bay reference site were further upstream.

$\mathrm{NE} / \mathrm{SW}$ or upstream direction, while the other $15 \mathrm{~m}$ transect was oriented perpendicular (across) to the shore, usually in a N/S or shore-line direction. For each transect, a meter tape was attached at the base of the artificial structure. Sediment cores were taken with a $10 \mathrm{~cm}$ high and $7 \mathrm{~cm}$ diameter plastic push core $\left(38.47 \mathrm{~cm}^{2}\right)$. Cores were taken at $0 \mathrm{~m}, 5 \mathrm{~m}, 10 \mathrm{~m}$ and $15 \mathrm{~m}$ from the artificial structure. We collected two cores at each distance, therefore collecting a total of 16 sediment samples at each artificial structure. Each core was transferred underwater into its respective pre-labeled Ziploc bag. At the control sites, the same sediment collection methods were used, except the transect tape was attached to the weight anchoring the ascent/descent line.

Upon return to the lab, the sediment samples were held at $4^{\circ} \mathrm{C}$ and processed within 24 hours. First, a subsample of sediment was retained for grain size analysis. Then the remainder of the sample was sieved through a $1 \mathrm{~mm}$ sieve. Macro-organisms larger than $1 \mathrm{~mm}$ were preserved in $10 \%$ formalin for 24 hours, then transferred to $70 \%$ ethanol. We identified all collected organisms to the lowest possible taxonomic level using a dissecting microscope. For the grain size analysis, $30 \%$ hydrogen peroxide was added to $30 \mathrm{~g}$ of the sediment subsample to remove any organic material in the sample. To prevent flocculation, 5\% sodium hexametaphosphate (SHMP) was then added to the samples and decanted off when the sediment particles had settled to the bottom. We analyzed processed sediment in a Beckman Coulter laser particle size analyzer. In this study, fine sand is defined as sediment with grain sizes between $125 \mu \mathrm{m}$ to $250 \mu \mathrm{m}$ while medium sand is between $250 \mu \mathrm{m}$ to $500 \mu \mathrm{m}$ (Wentworth 1922).

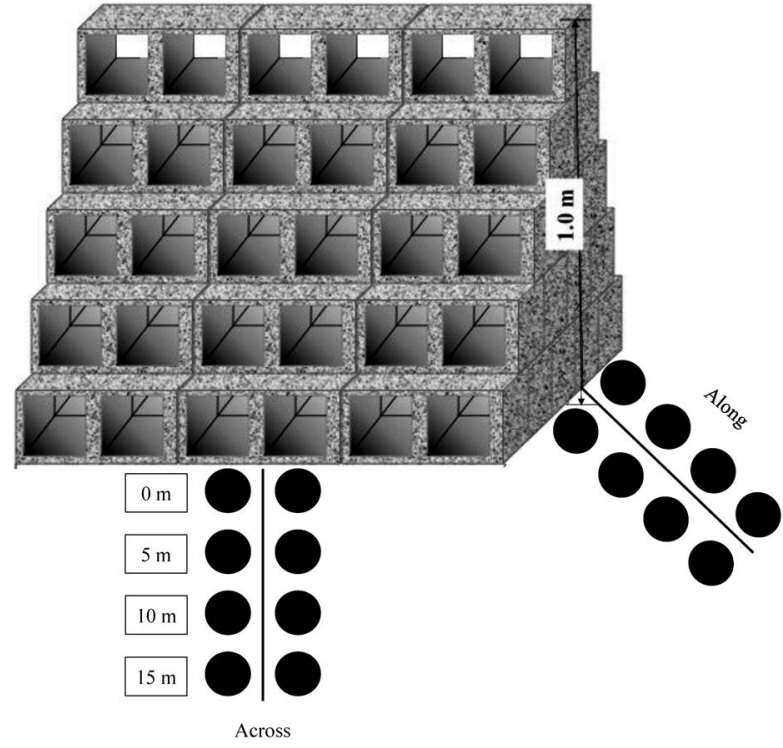

Fig. 2. Schematic of sampling method around artificial structures. Circles represent a sediment core; two cores were taken at 0 , 5,10 and $15 \mathrm{~m}$ away from each structure or arbitrary starting point at the reference sties. Transects were oriented along (parallel) to the shore and across (perpendicular) to the shore.

\section{Statistical Analyses}

We were primarily interested in differences in sediment characteristics [median grain size and percent of fines (percent of sample that is less than $62.5 \mu \mathrm{m}$, defined as silt or clay)] and macrofaunal communities between areas where artificial structures were placed and reference areas (test of "treatment") and secondarily if such an effect could be tracked with increasing distance away from the structure ("distance"). However, we also needed to take into account the effects of direction (cross versus along flow) and location (lower versus upper estuary) on these responses. We conducted all analyses using the mean values of the two cores at each distance in each direction as a sample. Two-way analysis of variance tests (ANOVAs) with direction and location in the bay as factors indicated no effect of direction on either sediment metric $(p=0.706$ and $p=0.369$ ), but location within the bay had a significant effect on both median grain size and percent fines $(p<0.001$ and $p<0.001$ ). Thus, for subsequent analyses we used the samples from the two directions as replicates and retained location in the bay as a factor.

We then analyzed sediment characteristics using a twoway ANOVA with the factors treatment (structure versus reference) and location within the bay with all the distances (in both directions) from the structures as replicates. Tukey's multiple comparison tests were conducted on the ANOVA models to determine how levels of a factor differed if ANOVA results were significant. We then used multiple linear regression on the samples collected from the artificial structure transects to test the effects of distance and location in the bay on both median grain 
size and percent of fine sediment. Following the linear regression, piecewise regressions, using input from a simple linear regression testing the effect of distance on median grain size, were run separately for the lower bay structures and the upper bay structure. The piecewise regression technique was used to evaluate if we could detect the edge of the artificial structure's zone of influence within the sampled $15 \mathrm{~m}$ distance. A piecewise regression identifies a breakpoint where the slope in the linear regression significantly changes (Muggeo 2008); in this case we interpreted a significant change in the slope to be a change in the effect of the structure.

Organismal indices (Shannon's index of diversity, richness, and total abundance metrics) (Magurran 1988) were compared between treatments and locations using a twoway ANOVA, again taking the mean of each sample and using the directions as the replicates. Next we again used linear regression to investigate the relationship between the organismal indices and distance from structure, keeping location as a factor, to determine if there was an effect of the structure on these indices. Finally, we conducted a linear regression between organismal indices and median grain size for each bay location to conclude if the sediment characteristics were correlated with the organismal indices. All univariate analyses were conducted in R statistical software (R Core Team 2016).

Prior to conducting multi-variate analyses, all infaunal density values were square-root transformed in PRIMER 6th edition (Clark and Gorley 2006) to down-weight the influence of dominant infauna. A matrix of Bray-Curtis similarities was computed on the transformed data and a cluster dendrogram (method="group average") and nonmetric multidimensional scaling plots (nMDS) were used to visualize the structure of the communities. A SIMPROF test was conducted when creating the cluster dendrogram to establish if there were any statistically distinct groups within the similarity matrix. SIMPER was used to investigate which organisms contributed to any differences in assemblages detected in the data. A nested two-way analysis of similarity (ANOSIM) was conducted to test if there were statistically significant differences in infaunal community composition between treatments within each bay location.

\section{Results}

\section{Sediment Analyses}

Overall, fine (125 $\mu \mathrm{m}$ to $250 \mu \mathrm{m})$ to medium ( $250 \mu \mathrm{m}$ to $500 \mu \mathrm{m})$ sand was collected from around AS1, AS2, and the Jetty reference site (Fig. 3a). Only fine sand was collected from around AS4 and the Bay reference site (Fig. $3 b)$. Although sediment differences were detected based on the location in the bay (median grain size: $\mathrm{F}_{1,36}=55.385$, $p<0.001$; percent of fine sediment: $F_{1,36}=142.659, p<0.001$ ), sediment samples collected parallel to shore were not sig- nificantly different from sediment collected perpendicular to shore when analyzing median grain size $\left(F_{1,36}=0.145\right.$, $\mathrm{p}=0.7055)$ or percent of fine sediment $\left(\mathrm{F}_{1,36}=0.827\right.$, $\mathrm{p}=0.369)$.

For median grain size, while there was not an overall significant effect of treatment on median grain size $\left(F_{1,36}=0.361, p=0.552\right)$, the interaction between treatment and location in the bay was nearly significant $\left(F_{1,36}=3.521\right.$, $\mathrm{p}=0.069$ ) and the locations in the bay were still distinct $\left(\mathrm{F}_{1,36}=59.506, \mathrm{p}<0.001\right)$. There was no overall effect of treatment on the percent of fines $\left(\mathrm{F}_{1,36}=0.183, \mathrm{p}=0.671\right)$ with locations in the bay still distinct $\left(\mathrm{F}_{1,36}=159.997\right.$,

(a)

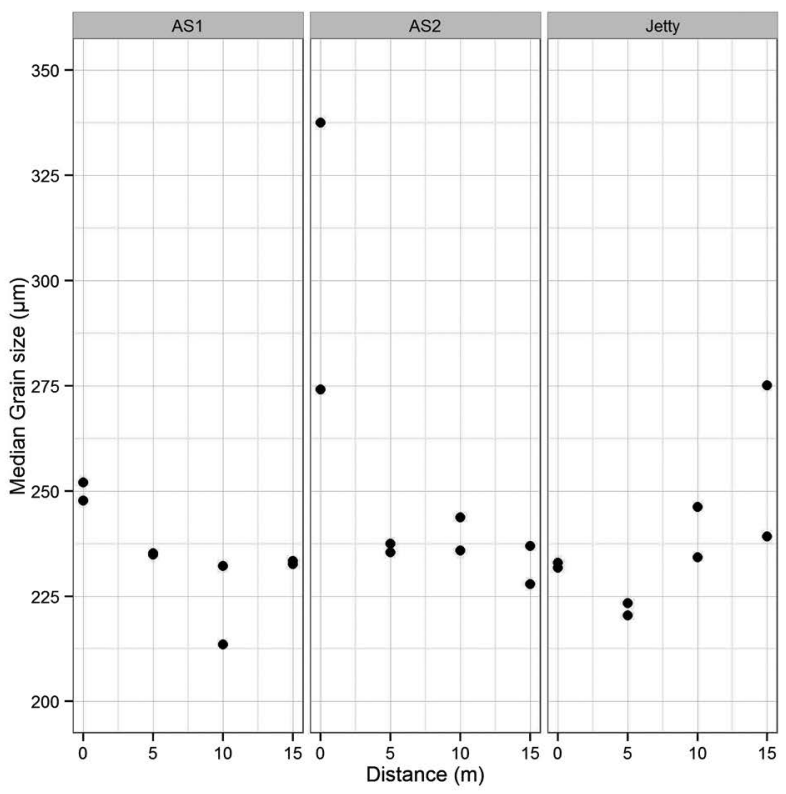

(b)

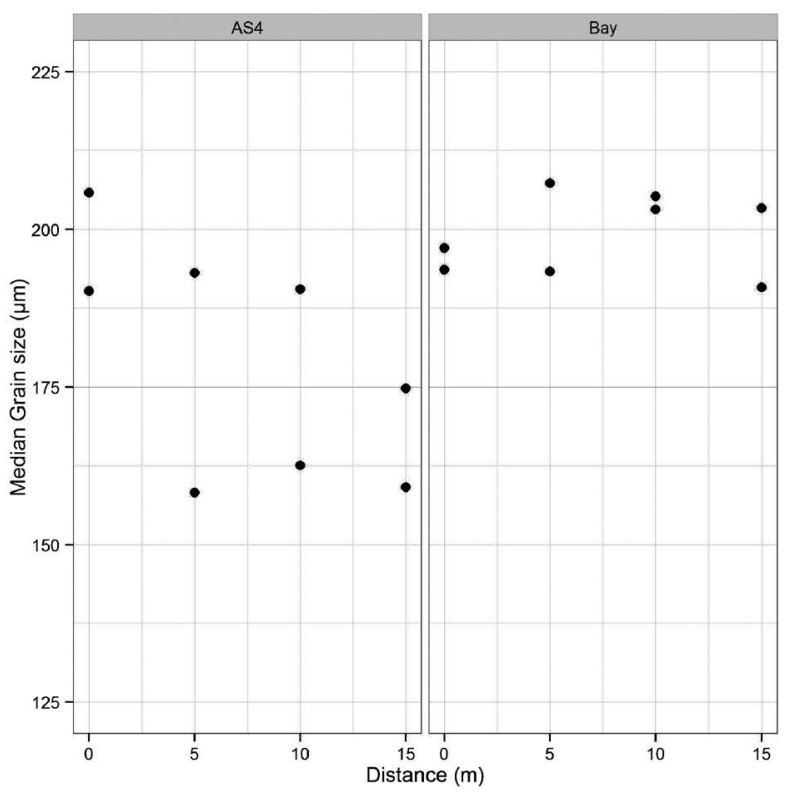

Fig. 3. Sediment median grain size at the (a) lower and (b) upper bay locations. Each distance is measured from the base of the artificial structures (AS1 and AS2, or AS4) and from an arbitrary starting point at the reference sites (“Jetty" or "Bay"). 
Table 1. Summary of results from multiple linear regression statistical tests conducted on sediment characteristics. The Slope gives the slope estimate from the regression output. The linear regression was conducted using the combined data from all three structures, while the piecewise regression was conducted separately for each location. The estimated breakpoint and the associated standard error for each breakpoint are shown for each location.

\begin{tabular}{|c|c|c|c|c|}
\hline \multirow{2}{*}{ Linear Regression } & \multicolumn{2}{|c|}{ Median Grain Size } & \multicolumn{2}{|c|}{ Percent Fines } \\
\hline & Slope & $\mathrm{p}$ & Slope & $\mathrm{p}$ \\
\hline Intercept & 265.36 & $<0.001$ & 0.591 & 0.216 \\
\hline Distance (0 to $15 \mathrm{~m})$ & -2.80 & 0.009 & -0.037 & 0.466 \\
\hline Location & -72.22 & $<0.001$ & 3.557 & $<0.001$ \\
\hline Distance $\times$ Location Interaction & 0.95 & 0.574 & 0.404 & $<0.001$ \\
\hline Piecewise regression results & $\begin{array}{r}\text { Lower: estin } \\
\text { st. } \\
\text { Upper: }\end{array}$ & $\begin{array}{l}\text { th at } 5.66 \\
.018 \\
\text { termined }\end{array}$ & & \\
\hline
\end{tabular}

$\mathrm{p}<0.001)$ and no significant interaction $\left(\mathrm{F}_{1,36}=1.861\right.$, $\mathrm{p}=0.181)$ was detected.

Linear regression, conducted on all three structures together, indicated an effect of distance away from structure on median grain sizes, and this was detected in both locations in the bay (Table 1). Median grain size significantly decreased as distance increased from artificial structure $(p=0.009)$. Additionally, median grain size in the lower bay was significantly different from the upper bay $(p<0.001)$. Piecewise regression conducted on median grain size from pooled lower bay AS1 and AS2 samples with a hypothesized breakpoint of $5 \mathrm{~m}$ indicated a significant breakpoint at $5.669 \mathrm{~m}(\mathrm{p}=0.018$; Fig. 3a). No significant breakpoint for median grain size around AS4 was found (Fig. 3b).

Linear regression indicated the percent of fine sediment did not significantly vary with increasing distance $(\mathrm{p}=0.466$; Table 1), although the interaction between location and distance was significant $(p<0.001)$. This was expected because fine sediment was not found in the majority of samples collected from the two downstream structures or from the Jetty site and the percent of fine sediment at the artificial structures ranged from 0 to $1.5 \%$ (Fig. $4 a$ ). In contrast, fine sediment was found in all samples from AS4 and the Bay site and the AS4 samples had a wider range ( 0 to $15 \%$ ) of percent of fine sediment (Fig. $4 b$ ). Location once again showed a significant effect on the percent of fine sediment $(\mathrm{p}<0.001)$.

\section{Infaunal Community Analyses}

A total of 410 annelids, 87 bivalves, 11 gastropods, 15 amphipods, and 1 Amphipholis sp. were collected and identified to the family taxonomic level whenever possible. Two-way ANOVAs indicated that treatment (artificial structure or reference) did not have a significant effect $(\mathrm{p}>0.5)$ on Shannon diversity, richness, or abundance (Table 2), although locations in the bay were significant $(p<0.001)$ with the upper bay having higher values for all three metrics. In terms of abundance, there was variability among distances at the Bay and Jetty reference sites.
The variability in abundance among the different distances around the artificial structures showed a trend related to distance that was significant $(\mathrm{p}=0.022)$ with abundances lowest at the furthest distances (Fig. 5; Table 3a); location in the bay was nearly significant $(\mathrm{p}=0.078)$. Regression analysis did not show a significant relationship between infaunal abundance and median grain size in the upper or lower bay $(p=0.581$ and 0.659 ; Table $3 b, c)$. Shannon diversity, however, showed no effect of distance from the artificial structures $(p=0.758)$, and the locations in the bay were not significantly different from one another $(p=0.291$; Table 3a). Again, Shannon diversity was not significantly related to median grain size in the upper or lower bay ( $p=0.342$ and $p=0.164$, respectively; Table $3 b, c)$. Richness also did not show a significant effect of distance from the structures $(p=0.148)$, but location in bay was significant $(p=0.041)$. As with abundance and diversity, median grain size did not show an effect on richness in the upper or lower bay ( $\mathrm{p}=0.522$ and 0.160 , respectively; Table $3 \mathrm{~b}, \mathrm{c}$ ).

Cluster analysis did not indicate statistically dissimilar groups of infaunal communities that were reflective of factors we were interested in (i.e. treatment and distance); however, there was some discernable structure in the data related to our experimental factors (Fig. 6). The majority of samples from the Bay reference site and AS4 site grouped together in a cluster that was most dissimilar from other clusters; within this cluster, most of the AS4 samples were distinct from the reference samples. An nMDS plot further revealed distinctions based on location in the bay and treatment (Fig. 7). In the nMDS plot, the upper and lower bay samples did not overlap. Again, within the upper bay, the reference samples were largely distinct from the AS4 samples. Within the lower bay, the reference locations were tightly clustered (quite similar infaunal communities) while the AS1 and AS2 samples were highly variable and had little overlap with reference samples. Overall, both sets of reference samples were tightly clustered towards the lower right of the plot while the artificial structure samples scattered toward the upper left. Despite these visible differences, a nested two-way ANOSIM (treatment nested in 
(a)

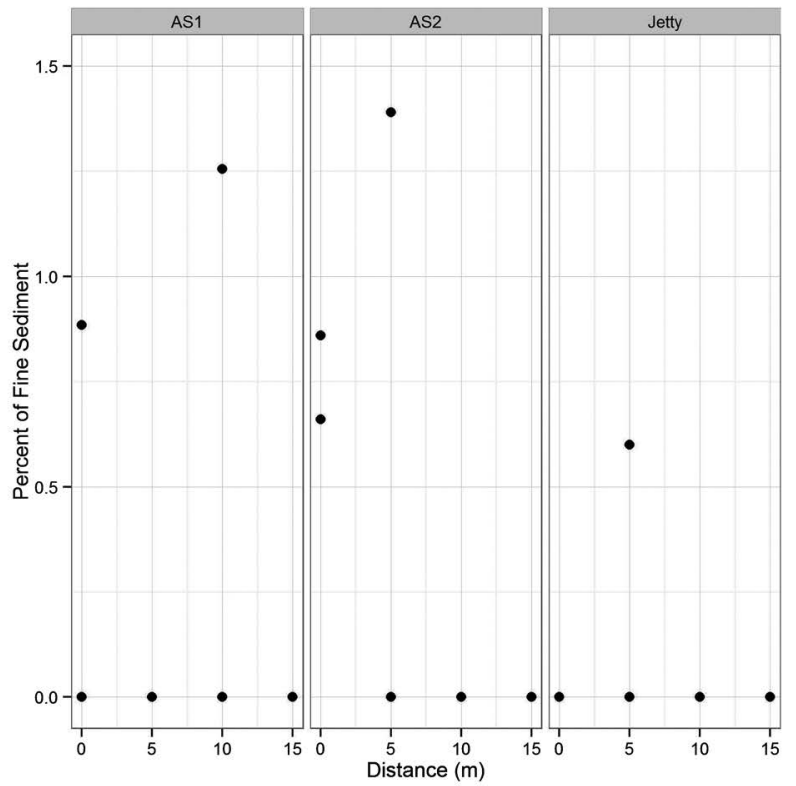

(b)

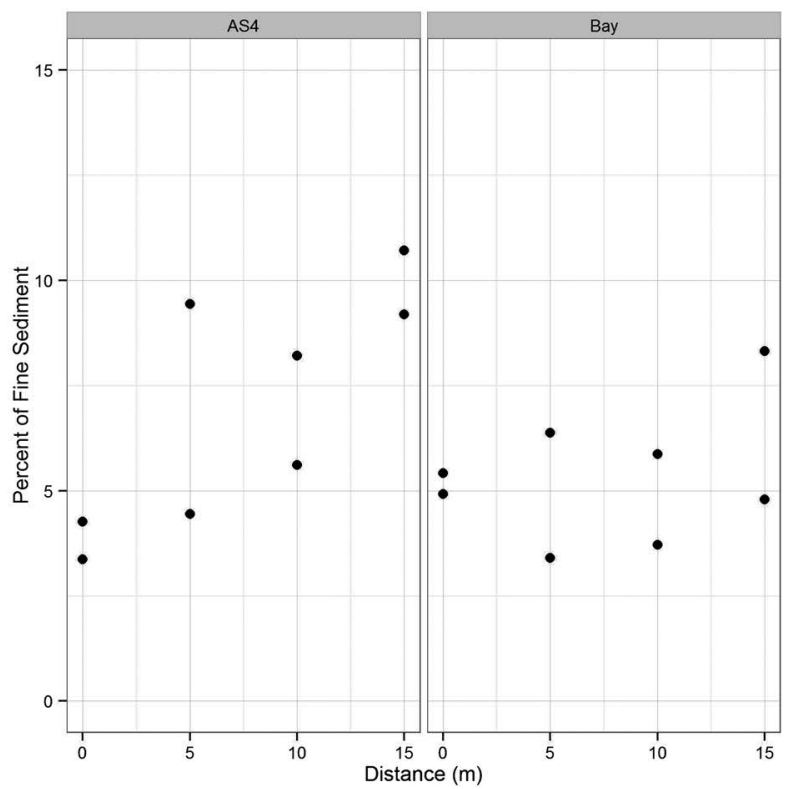

Fig. 4. Percent of fine sediment (sediment less than $62.5 \mu \mathrm{m}$ ) at the (a) lower and (b) upper bay locations. Each distance is measured from the base of the artificial structures (AS1 and AS2, or AS4) and from an arbitrary starting point at the reference sites (“Jetty" or “Bay"). location) showed a significant but small effect of treatment on the infaunal communities $(\mathrm{R}=0.194 ; \mathrm{p}=0.024)$.

Despite the lack of statistically significant differences in assemblages among the treatments and locations in the bay, we conducted a SIMPER analysis to investigate what taxa were contributing to the apparent patterns in the cluster and nMDS plots. Within the lower bay the artificial structures and reference samples had an average dissimilarity of $71 \%$ (Table 4). Here, Nephtyidae and Spionidae were present in low numbers in the reference samples but absent in the artificial structure samples, Capitellidae were slightly more abundant and Goniadidae were much more abundant in the reference samples as compared to the ar-

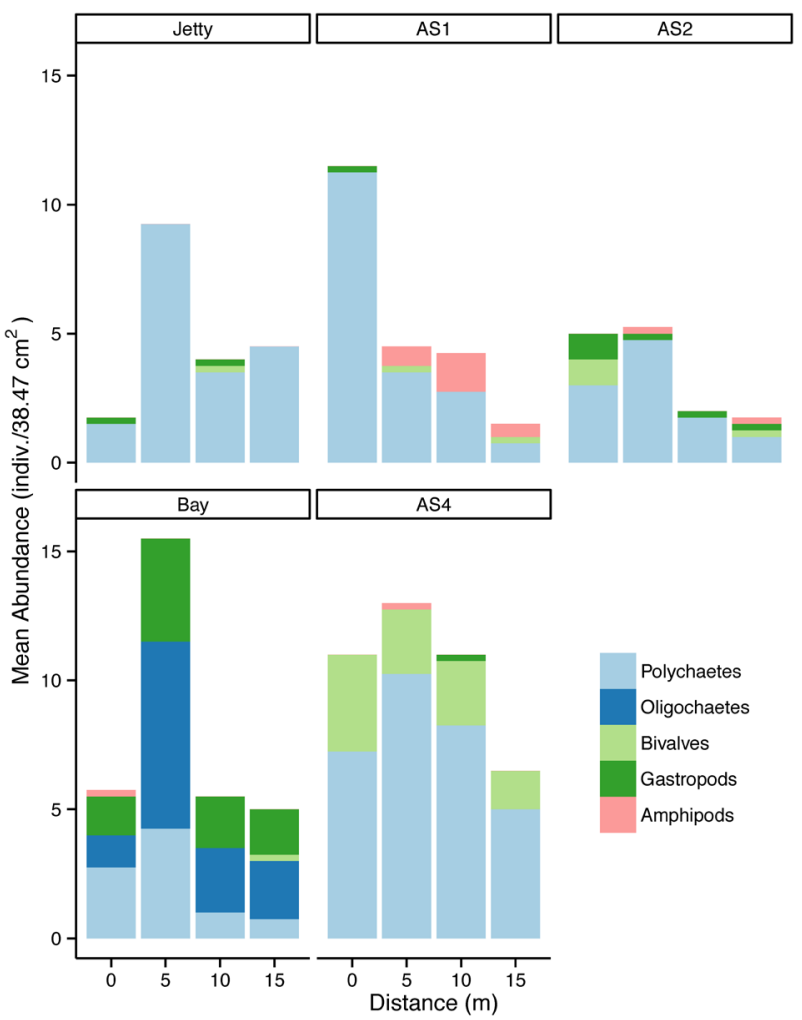

Fig. 5. Mean abundance (individuals per $38.47 \mathrm{~cm}^{2}$ core) of major infaunal taxa at each distance from the artificial structure or reference point for each site. Infaunal taxa with less than ten individuals collected from all samples were not plotted to improve figure clarity.

Table 2. Summary of results from two-way ANOVA statistical test conducted on infaunal community metrics. F gives the F-value from the ANOVA output and the df gives the degrees of freedom. The two-way ANOVA used artificial structure and reference site data.

\begin{tabular}{|c|c|c|c|c|c|c|c|c|c|}
\hline \multirow{2}{*}{ Two-way ANOVA } & \multicolumn{3}{|c|}{ Shannon diversity } & \multicolumn{3}{|c|}{ Richness } & \multicolumn{3}{|c|}{ Abundance } \\
\hline & df & $\mathrm{F}$ & $\mathrm{p}$ & df & $\mathrm{F}$ & $\mathrm{p}$ & df & $\mathrm{F}$ & $\mathrm{p}$ \\
\hline Treatment (structure vs. reference) & 1 & 1.5 & 0.229 & 1 & 2.149 & 0.151 & 1 & 0.009 & 0.924 \\
\hline Location (Upper vs. Lower Bay) & 1 & 20.232 & $<0.001$ & 1 & 28.482 & $<0.001$ & 1 & 10.728 & 0.002 \\
\hline Treatment $\times$ Location Interaction & 1 & 1.094 & 0.303 & 1 & 0.334 & 0.567 & 1 & 0.797 & 0.378 \\
\hline Residuals & 36 & & & 36 & & & 36 & & \\
\hline Tukey multiple comparison tests & \multicolumn{3}{|c|}{ Upper $>$ Lower } & \multicolumn{3}{|c|}{ Upper $>$ Lower } & & \multicolumn{2}{|c|}{ Upper $>$ Lower } \\
\hline
\end{tabular}


Table 3. Summary of multiple linear regression statistical tests conducted on infaunal community metrics. The Slope gives the slope estimate from the regression output. The linear regressions were conducted only using data collected from artificial structures.

\begin{tabular}{|c|c|c|c|c|c|c|c|}
\hline & \multirow{2}{*}{ Linear Regressions } & \multicolumn{2}{|c|}{ Shannon diversity } & \multicolumn{2}{|c|}{ Richness } & \multicolumn{2}{|c|}{ Abundance } \\
\hline & & Slope & $\mathrm{p}$ & Slope & $\mathrm{p}$ & Slope & $\mathrm{p}$ \\
\hline \multirow[t]{4}{*}{$\mathrm{a}$} & Intercept & 0.864 & $<0.001$ & 3.700 & $<0.001$ & 7.7625 & $<0.001$ \\
\hline & Distance (0 to $15 \mathrm{~m})$ & -0.005 & 0.758 & -0.085 & 0.148 & -0.410 & 0.022 \\
\hline & Location & 0.280 & 0.291 & 2.000 & 0.041 & 4.963 & 0.078 \\
\hline & Distance $\times$ Location Interaction & 0.012 & 0.668 & 0.025 & 0.255 & 0.105 & 0.717 \\
\hline \multirow[t]{2}{*}{$\mathrm{b}$} & Upper Bay: Intercept & -0.129 & 0.923 & 1.567 & 0.783 & 21.3 & 0.298 \\
\hline & Median grain size & 0.007 & 0.342 & 0.021 & 0.522 & -0.061 & 0.581 \\
\hline \multirow[t]{2}{*}{ c } & Lower Bay: Intercept & -0.260 & 0.732 & -0.922 & 0.738 & 0.668 & 0.942 \\
\hline & Median grain size & 0.004 & 0.164 & 0.016 & 0.160 & 0.016 & 0.659 \\
\hline
\end{tabular}

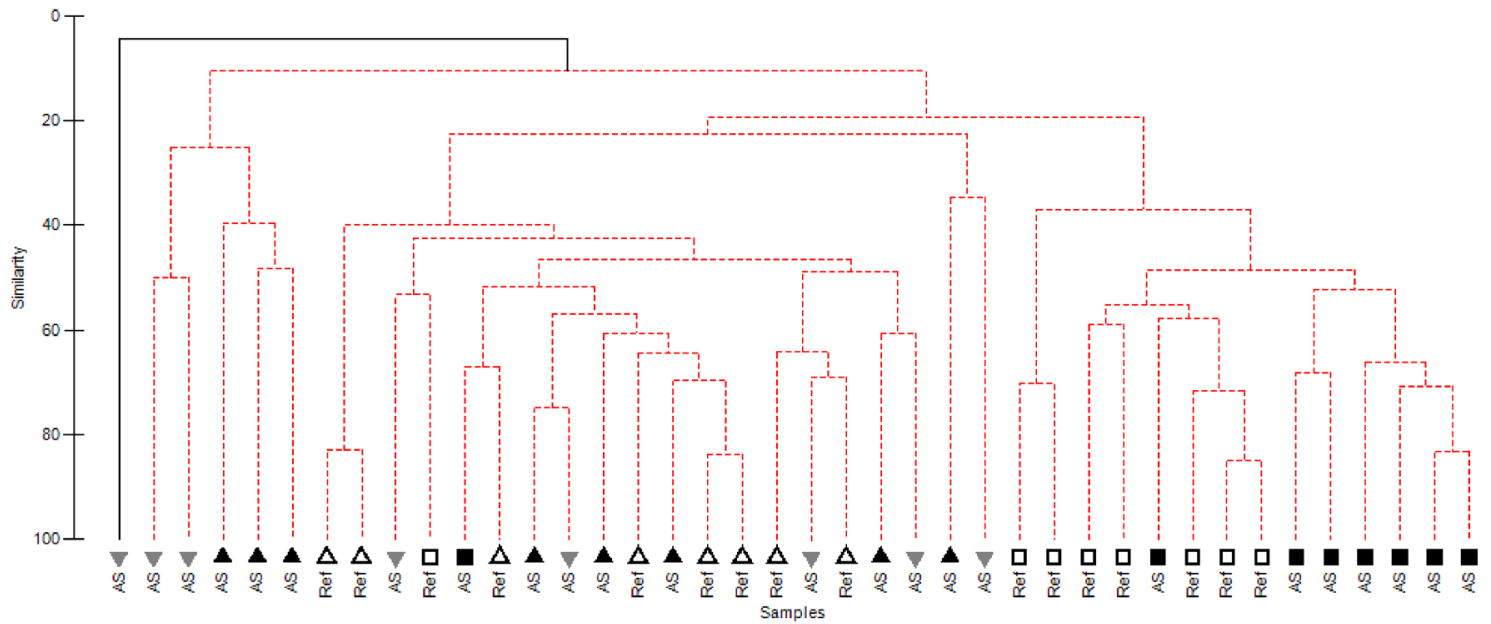

Fig. 6. A cluster analysis performed on the square-root transformed infaunal abundances from the artificial structures (AS) and the reference sites (Jetty and Bay). Artificial structure sites are represented by filled symbols, while the reference sites are open; lower bay samples are triangles and upper bay samples are squares. The group average method was used for this analysis. The dotted lines link statistically similar groups (SIMPROF).

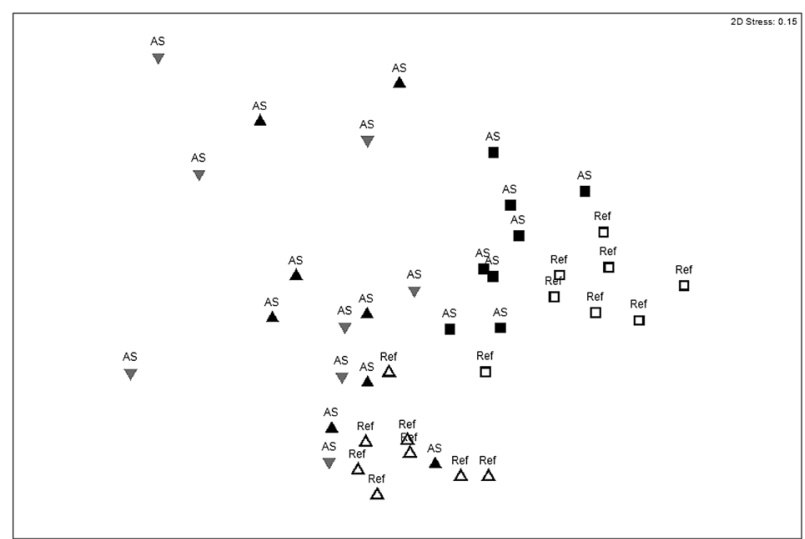

Fig. 7. An nMDS ordination plot comparing infaunal assemblages from each treatment labelled by location in Yaquina Bay. Symbols are described as for Figure 6. tificial structures. Phoxocephalidae, Orbiniidae, Magelonidae, Tellinidae, Nemertea, and the gastropod Callianax baetica were collected from the artificial structure samples but were absent from all reference samples. These differences were not reflected in the upper bay. In the upper bay Captiellidae and Goniadidae were collected in greater numbers from around the artificial structure, Tellinidae were abundant in both sets of samples, and Nemertea were absent from the artificial structure samples while present in the reference samples. The major difference in the upper bay was the high abundances of oligochaetes in the reference samples and their absence in the artificial structure samples. Additionally, at the upper bay artificial structure, Oweniidae tube worms were abundant but rare in the reference samples. In the upper bay, the artificial structure and reference samples had an average dissimilarity of $60 \%$. Within group similarity for the lower bay artificial structure samples averaged 26\% (as expected from the wide spread on the nMDS plot). The upper bay artificial struc- 
Table 4. Summary of the similarity percentages analysis (SIMPER) conducted for each location in the bay. Average square root abundance (individuals per $38.47 \mathrm{~cm}^{2}$ core) is shown for each species at each site. Cumulative \% shows the percentage that each species contributed to the average similarity in each location.

\begin{tabular}{|c|c|c|c|}
\hline \multirow[t]{2}{*}{ Lower Bay } & \multicolumn{3}{|c|}{ Average dissimilarity $=71.15 \%$} \\
\hline & AS $1 \& 2$ & Jetty Ref & \\
\hline Species & $\begin{array}{l}\text { Av.Sqrt } \\
\text { Abund }\end{array}$ & $\begin{array}{l}\text { Av. Sqrt } \\
\text { Abund }\end{array}$ & Cum.\% \\
\hline Capitellidae & 1.20 & 1.89 & 31.8 \\
\hline Unidentified polychaetes & 0.40 & 0.13 & 42.29 \\
\hline Goniadidae & 0.09 & 0.35 & 51.1 \\
\hline Phoxocephalidae & 0.32 & 0 & 59.9 \\
\hline Tellinidae & 0.25 & 0 & 65.5 \\
\hline Nemertea & 0.23 & 0 & 70.88 \\
\hline Callianax pycna & 0.11 & 0.09 & 74.64 \\
\hline Callianax baetica & 0.13 & 0 & 78.39 \\
\hline Orbiniidae & 0.17 & 0 & 82.13 \\
\hline Magelonidae & 0.15 & 0 & 85.19 \\
\hline Spionidae & 0 & 0.09 & 87.65 \\
\hline Nephtyidae & 0 & 0.09 & 90.03 \\
\hline \multirow[t]{2}{*}{ Upper Bay } & \multicolumn{3}{|c|}{ Average dissimilarity $=60.44 \%$} \\
\hline & AS 4 & Bay Ref & \\
\hline Species & $\begin{array}{l}\text { Av. Sqrt } \\
\text { Abund }\end{array}$ & $\begin{array}{l}\text { Av. Sqrt } \\
\text { Abund }\end{array}$ & Cum. \% \\
\hline Oligochaetes & 0 & 1.58 & 22.2 \\
\hline Oweniidae & 2.03 & 0.68 & 42.78 \\
\hline Capitellidae & 0.96 & 0.60 & 56.69 \\
\hline Goniadidae & 0.60 & 0.21 & 64.61 \\
\hline Tellinidae & 1.36 & 1.44 & 71.41 \\
\hline Unidentified polychaetes & 0.35 & 0 & 76.2 \\
\hline Montacutidae & 0.33 & 0 & 80.88 \\
\hline Orbiniidae & 0.27 & 0 & 84.75 \\
\hline Mytillidae & 0.09 & 0.18 & 87.88 \\
\hline Cardiidae & 0.13 & 0 & 89.56 \\
\hline Nemertea & 0 & 0.13 & 91.17 \\
\hline
\end{tabular}

ture and the reference locations each had within group similarities of $55 \%$ to $57 \%$.

\section{Discussion}

Developing in-stream tidal energy in estuarine environments, like Yaquina Bay, could affect infaunal communities by replacing their soft-sediment habitat with hard structure and causing additional physical changes to the surrounding benthos. The goal of this study was to determine how artificial structures affected the benthic habitat in terms of sediment composition and infaunal community composition. In both the lower and upper bay, median grain size increased significantly with proximity to struc- ture, and a trend of increasing fine sediment with increasing distance from a structure was seen where more fine sediment was present. Thus, our first hypothesis that sediment characteristics would be affected by structure was supported: the detectable effect ending at $5 \mathrm{~m}$ from the lower bay structures. These results concur with previous literature that demonstrate a trend of smaller grain sizes away from rocky reefs (Barros et al. 2001, Martins et al. 2013) with differences at $1 \mathrm{~m}$ versus further away from the reefs.

Traditional metrics of infaunal abundance, richness and diversity did not differ statistically between artificial structures and reference sites, largely rejecting our second hypothesis that communities surrounding the artificial structures would have different composition and be more diverse as compared to reference site communities. Although the grain size changes did not appear to result in heterogeneous conditions around the structures, the multivariate approach (nMDS) illustrated the heterogeneity of infaunal assemblages around the structures as compared to the reference areas, particularly in the lower bay. Additionally, there did appear to be an effect of structure on abundance, with higher abundance closer to the structures.

Although the pattern of greater infaunal invertebrate abundance closer to the structures than further away was not explained by sediment characteristics in our linear model, the findings are consistent with observations of other hard structures placed in sedimentary habitats. Higher abundances of infauna generally were found closer to the scour protection of a wind turbine in the North Sea where organic matter and chlorophyll $a(\mathrm{Chl} a)$ concentrations were higher than at distances further away (Coates et al. 2014). One hypothesis is that increased flow around a structure could facilitate a greater incorporation and mixing of organic matter and nutrients in the soft-sediment areas closest to the structure, thus attracting more organisms to the structure (Fabi et al. 2002, Falcão et al. 2009).

In our samples from Oregon, the greater abundances close to the structure were mostly due to increased polychaetes: Capitellidae at the lower bay structures and Oweniidae at AS4 in the upper bay. Similarly, higher abundances of Diopatra polychaetes have been found in sediments near both artificial reefs/structures and natural reefs in southern California (Turner et al. 1969, Emerson 1975, Davis et al. 1982). Capitella species are deposit feeders that have been shown to have opportunistic population dynamics demonstrated via their association with organic enrichment of sediment, which is often preceded by environmental disturbances (Tsutsumi 1990). Further studies by Tsutsumi et al. (1990) revealed that the growth of Capitella sp. was related to the addition of organic material to the sediment (i.e. algae). The artificial structures in our study supported macroalgae communities; thus the Capitellidae in our samples could have taken advantage of additional inputs of organic matter to their sediment habitat, such as decaying algae or other falling organisms coming 
from the structure. This mechanism might explain why abundances were not explained by sediment characteristics that we measured. Future work should consider quantifying organic matter and/or chlorophyll $a$ concentrations in collected sediment samples.

Because variations in the composition of the infauna did not appear to be correlated with changes seen in sediment characteristics and significant differences were not detected between the AS and reference locations, we rejected our second hypothesis. This is in contrast to Barros et al. (2001) and Martins et al. (2013) who found larger grain sizes (coarse sand and gravel) with proximity to a natural rocky reef and also found significant differences in infaunal community composition adjacent to the reefs compared to $11-16 \mathrm{~m}$ away from the reefs. In southern California, Ambrose \& Anderson (1990) also found coarser sediments $(>500 \mu \mathrm{m})$ closer to an artificial reef than at 10 or $20 \mathrm{~m}$ away and showed differences in infaunal composition closer to the reef versus various distances further away. The sediment collected for our study did not have any coarse sand or gravel, so perhaps changes in grain size need to be greater than we observed in order to result in statistically significant differences in infaunal composition. As in our study, Davis et al. (1982) discovered no significant relationship between distance from artificial reefs and infaunal communities; however, they did detect significant trends for a number of infaunal taxa related to distance from an oil platform. Consequently, the relationship between infauna and sediment appears to be influenced by a variety of environmental variables. In our study, effects of artificial structures on infaunal organisms were suggestive but not statistically significant and were particularly weak relative to the high variability of infaunal communities the estuary.

If more marine development occurs in estuarine areas of Oregon, such as with the deployment of in-stream tidal energy, our results indicate expected long-term benthic effects of these devices might be minimal and limited to the area immediately surrounding the structure as long as the environmental conditions, physical footprint and structure of the devices are similar to the Yaquina Bay environment and artificial structures used in this study. Yaquina Bay has an average current speed of $1.9 \mathrm{~m} \mathrm{~s}^{-1}$ (NOAA 2014), and most in-stream tidal energy requires a current speed of 1.5 to $3.5 \mathrm{~m} \mathrm{~s}^{-1}$. Thus actual tidal energy devices would probably be deployed in tidal channels with similar and possibly greater flow than that found in Yaquina Bay. Additionally, the size of tidal energy devices and their foundations, more specifically their physical footprint, likely would affect the extent of scour around a device and change the magnitude of benthic effects. The physical footprint of current tidal energy devices can vary in size, from having a $0.3 \mathrm{~m}^{2}$ footprint to a $12 \mathrm{~m}^{2}$ footprint, and also in scale, with certain devices having one or multiple foundations for a single device (Polagye et al. 2010). In addition, a commercial scale production of tidal energy would most likely contain multiple tidal energy devices in a site, so the benthic effects observed could also be influenced by the proximity of other devices in an area. Thus, the non- or marginally-significant effects on infauna detected in our study could scale up to be more significant and have ecological consequences with the deployment of larger and/or multiple devices.

Despite the small scale of our installations, our results coincide with previous studies on the distance effects of artificial reefs or structures on the offshore benthic communities on the U.S. west coast (Davis et al. 1982, Ambrose \& Anderson 1990, Glaholt 2008). Still, it appears that greater differences in infaunal communities are caused by differences in sediment composition among different locations in the estuary. The high variability in physical factors in a dynamic estuarine system could play a larger role in dictating the composition and configuration of infaunal communities in the bay than the presence of an artificial structure. Further studies that specifically look at a wider range of environmental factors, such as organic matter or chlorophyll concentrations, would be beneficial to better understand the drivers of variability of infaunal communities in this estuary and understand how artificial structures influence that variability. Conducting additional studies that look into possible predation effects would also elucidate possible trophic changes that could occur if infaunal communities are influenced by artificial structures. If infaunal predators, such as juvenile rockfish, more frequently use artificial structures, then changes to the infauna in the vicinity could affect these predators and/or the infauna might be more greatly affected by the presence of artificial structures. Previous studies have seen a decrease of infaunal organisms near natural and artificial reefs and have speculated predation could be a factor for the observed abundance pattern (Posey \& Ambrose 1994, Barros et al. 2001, Langlois et al. 2005). Hence, information should be gathered about additional organisms that utilize artificial structures in areas where MRE devices are sited to get a full picture of the possible effects. Nevertheless, since the effects we detected on sediment characteristics did not result in changes to the structure of the infaunal communities and in fact increased their abundance at the distances closest to the structures, in an estuarine environment like Yaquina Bay, we would not expect adverse effects from similar artificial structures on species that forage on the infauna.

\section{Acknowledgements}

We thank Scott Heppell (OSU) and Scott Marion (ODFW) for providing guidance and support throughout all the stages of this project. We are grateful to the Heppell lab for providing us with the information, resources and the artificial structures that were the foundation of this research. The dives required for this project would not have been possible without the cheerful assistance from Captain Paul Tate and many volunteer dive buddies. Kevin Buch 
(OSU) and the scientific diving program at OSU were also instrumental for providing resources necessary for completing the field work. We also thank the U.S. Department of Energy for providing support for the authors during this project under Award Number DE-FG36-08GO18179. Disclaimer: This report was prepared as an account of work sponsored by an agency of the United States Government. Neither the United States Government nor any agency thereof, nor any of their employees, makes any warranty, expressed or implied, or assumes any legal liability or responsibility for the accuracy, completeness, or usefulness of any information, apparatus, product, or process disclosed, or represents that is use would not infringe privately owned rights. Reference herein to any specific commercial product, process, or service by trade name, trademark, manufacturer, or otherwise does not necessarily constitute or imply its endorsement, recommendation, or favoring by the United States Government or any agency thereof. Their views and opinions of the authors expressed herein do not necessarily state or reflect those of the United States Government or any agency thereof.

\section{References}

Ambrose RF, Anderson TW (1990) Influence of an artificial reef on the surrounding infaunal community. Mar Biol 107: 41-52.

Barros F, Underwood AJ, Lindegarth M (2001) The influence of rocky reefs on structure of benthic macrofauna in nearby softsediments. Estuar Coast Shelf Sci 52: 191-199.

Bedard R, Previsic M, Siddiqui O, Hagerman G, Robinson M (2005) Final survey and characterization tidal in stream energy conversion (TISEC) devices. EPRI-TP-004 NA.

Boehlert GW, Gill AB (2010) Environmental and ecological effects of ocean renewable energy development: a current synthesis. Oceanography 23: 68-81.

Broadhurst M, Orme CDL (2014) Spatial and temporal benthic species assemblage responses with a deployed marine tidal energy device: a small scaled study. Mar Environ Res 99: 76-84.

Clarke KR, and Gorley RN (2006) PRIMER v6: User Manual/ Tutorial. Plymouth: PRIMER-E. 192 p.

Coates DA, Deschutter Y, Vincx M, Vanaverbeke J (2014) Enrichment and shifts in macrobenthic assemblages in an offshore wind farm area in the Belgian part of the North Sea. Mar Environ Res 95: 1-12.

Coblentz KE, Henkel JR, Sigel BJ, Taylor CM (2015) Influence of sediment characteristics on the composition of soft-sediment intertidal communities in the northern Gulf of Mexico. PeerJ 3, e1014-e1014.

Connell SD, Glasby TM (1999) Do urban structures influence local abundance and diversity of subtidal epibiota? A case study from Sydney Harbour, Australia. Mar Environ Res 47: 373-387.

Conway F, Stevenson J, Hunter D, Stefanovich M, Campbell H, Covell Z, Yin Y (2010) Ocean space, ocean place: the human dimensions of wave energy in oregon. Oceanography 23: $82-91$.

Dauble A (2010) Young-of-the-year rockfish (Sebastes spp.) set- tlement dynamics in oregon estuaries. MS thesis. Oregon State University. USA.

Davis N, VanBlaricom GR, Dayton PK (1982) Man-made structures on marine sediments: effects on adjacent benthic communities. Mar Biol 70: 295-303.

Emerson RR (1975) The biology of a population of Diopatra ornata at Santa Catalina Island, California. $\mathrm{PhD}$ thesis. University of Southern California. USA.

Fabi G, Luccarini F, Panfili M, Solustri C, Spagnolo A (2002) Effects of an artificial reef on the surrounding soft-bottom community (central Adriatic Sea). ICES J Mar Sci 59: 343-349.

Falcão M, Santos MN, Drago T, Serpa D, Monteiro C (2009) Effect of artificial reefs (southern Portugal) on sediment-water transport of nutrients: Importance of the hydrodynamic regime. Estuar Coast Shelf Sci 83: 451-459.

Gill AB (2005) Offshore renewable energy: ecological implications of generating electricity in the coastal zone. J Appl Ecol 42: 605-615.

Glaholt RD (2008) Investigation of the potential effects of marine pipelines on dungeness crab movement and benthic ecology. Eighth Int Symp Environ Concerns Rights-of-w Manag 679-692.

Gray JS (1974) Animal-sediment relationships. Oceanogr Mar Biol An Annu Rev 12: 223-261.

Halpern BS, Walbridge S, Selkoe KA, Kappel CV, Micheli F, D'Agrosa C, Bruno JF, Casey KS, Ebert C, Fox HE, Fujita R, Heinemann D, Lenihan HS, Madin EMP, Perry MT, Selig ER, Spalding M, Steneck R, Watson R (2008) A global map of human impact on marine ecosystems. Science 319: 948-952.

Henkel SK, Conway FDL, Boehlert GW (2013) Environmental and human dimensions of ocean renewable energy development. Proc IEEE 101: 991-998.

Hiscock K, Tyler-Walters H, Jones H (2002) High level environmental screening study for offshore wind farm developments-Marine Habitats and Species Project. Report from the Marine Biological Association to the The Department of Trade and Industry New \& Renewable Energy Programme (AEA Technology, Environment Contract: W/35/00632/00/00.)

Hoegh-Guldberg O, Bruno JF (2010) The impact of climate change on the world's marine ecosystems. Science 328: 15231528.

Hogue EW, Carey AG (1982) Feeding ecology of 0-age flatfishes at a nursery ground on the Oregon coast. Fish Bull 80: 555565 .

Holloway MG, Connell SD (2002) Why do floating structures create novel habitats for subtidal epibiota? Mar Ecol Prog Ser 235: 43-52.

Inger R, Attrill MJ, Bearhop S, Broderick AC, Grecian WJ, Hodgson DJ, Mills C, Sheehan E, Votier SC, Witt MJ, Godley BJ (2009) Marine renewable energy: potential benefits to biodiversity? An urgent call for research. J Appl Ecol 46: 11451153.

Langhamer O, Wilhelmsson D, Engström J (2009) Artificial reef effect and fouling impacts on offshore wave power foundations and buoys-a pilot study. Estuar Coast Shelf Sci 82: 426-432.

Langlois TJ, Anderson MJ, Babcock RC (2005) Reef associated predators influence adjacent soft-sediment communities. Ecol- 
ogy 89: $1508-1519$.

Magurran AE (1988) Ecological Diversity and Its Measurement. Chapman \& Hall, Bangor, UK. 179 pp.

Mannino A, Montagna PA (1997) Small-scale spatial variation of macrobenthic community structure. Estuaries 20: 159-173.

Martins GM, Faria J, Rubal M, Neto AI (2013) Linkages between rocky reefs and soft-bottom habitats: Effects of predation and granulometry on sandy macrofaunal assemblages. J Sea Res 81: 1-9.

Miller RG, Hutchison ZL, Macleod AK, Burrows MT, Cook EJ, Last KS, Wilson B (2013) Marine renewable energy development: assessing the benthic footprint at multiple scales. Front Ecol Environ 11: 433-440.

Muggeo VMR (2008) segmented: An R package to Fit Regression Models with Broken-Line Relationships. R News 8: 20 25.

NOAA. National Ocean and Atmospheric Sciences (2014) Current station locations and ranges.Yaquina Bay. Available at: https://tidesandcurrents.noaa.gov/currents15/tab2pc2.html\#11 (accessed on 17 October 2016).

Pearson TH, Rosenberg R (1978) Macrobenthic succession in relation to organic enrichment and pollution of the marine environment. Oceanogr Mar Biol An Annu Rev 16: 229-311.

Perkol-Finkel S, Benayahu Y (2007) Differential recruitment of benthic communities on neighboring artificial and natural reefs. J Exp Mar Bio Ecol 340: 25-39.

Polagye B, Copping A, Kirkendall K, Boehlert G, Walker S, Wainstein M, van Cleve B (2010) Environmental effects of tidal energy development: a scientific workshop. Workshop Briefing Paper. University of Washington. USA. Available at: http://depts.washington.edu/nnmrec/workshop/docs/Tidal energy_briefing_paper.pdf (accessed on 10 July 2016).

Posey MH, Ambrose Jr. WG (1994) Effects of proximity to an offshore hard-bottom reef on infaunal abundances. Mar Biol 118: 745-753.

Punt MJ, Groeneveld RA, van Ierland EC, Stel JH (2009) Spatial planning of offshore wind farms: A windfall to marine environmental protection? Ecol Econ 69: 93-103.

R Core Team (2016) R: A language and environment for statistical computing. R Foundation for Statistical Computing, Vienna, Austria. Available at: https://www.R-project.org/ (accessed on 15 April 2016)

Sivadas S, Ingole B, Nanajkar M (2010) Benthic polychaetes as good indicators of anthropogenic impact. Indian J Mar Sci 39:
201-211.

Smith RW, Bergen M, Weisberg SB, Cadien D, Dalkey A, Montagne D, Stull JK, Velarde RG (2001) Benthic response index for assessing infaunal communities on the southern California mainland shelf. Ecol Appl 11: 1073-1087.

Southard J (2006) 12.090 Special Topics: An Introduction to Fluid Motions, Sediment Transport, and Current-generated Sedimentary Structures. MIT OpenCourseWare: Massachusetts Institute of Technology. USA. Available at: http://ocw. mit.edu/courses/earth-atmospheric-and-planetary-sciences/12090-special-topics-an-introduction-to-fluid-motions-sedimenttransport-and-current-generated-sedimentary-structuresfall-2006 (accessed on 10 July 2016)

Thresher R, Musial W (2010) Ocean renewable energy's potential role in supplying future electrical needs. Oceanography 23: $16-21$.

Tsutsumi H (1990) Population persistence of Capitella sp (Polychaeta; Capitellidae) on a mud flat subject to environmental disturbance by organic enrichment. Mar Ecol Prog Ser 63: 147-156.

Tsutsumi H, Fukunaga S, Fujita N, Sumida M (1990) Relationship between growth of Capitella sp. and organic enrichment of the sediment . Mar Ecol Prog Ser 63: 157-162.

Turner CH, Ebert EE, Given RR (1969) Man-Made Reef Ecology. California Department of Fish and Game, Sacramento, California, $221 \mathrm{pp}$.

Wentworth CK (1922) A scale of grade and class terms for clastic sediments. J Geol 30: 377-392.

Widdicombe S, Somerfield PJ (2012) Marine biodiversity: its past development, present status, and future threats. In: Marine Biodiversity Ecosystem Functioning: Frameworks, Methodologies, and Integration (eds Solan M, Aspden RJ, and Paterson DM). Oxford University Press, Oxford, pp. 1-15.

Wilson JC (2007) Offshore wind farms: their impacts, and potential habitat gains as artificial reefs, in particular for fish. MS thesis. University of Hull, UK.

Wilson JC, Elliott M, Cutts ND, Mander L, Mendão V, PerezDominguez R, Phelps A (2010) Coastal and offshore wind energy generation: is it environmentally benign? Energies 3: 1383-1422.

Yeung C, Yang M-S, McConnaughey RA (2010) Polychaete assemblages in the south-eastern Bering Sea: linkage with groundfish distribution and diet. J Mar Biol Assoc UK 90: 903-917. 